\title{
Paradoxes of French accreditation
}

\author{
M-P Pomey, P François, A-P Contandriopoulos, A Tosh, D Bertrand
}

Qual Saf Health Care 2005;14:51-55. doi: 10.1136/qshc.2004.011510

The accreditation system introduced into the French healthcare system in 1996 has five particular characteristics: (1) it is mandatory for all healthcare establishments; (2) it is performed by an independent government agency; (3) surveyors have to report all instances of non-compliance with safety regulations; (4) the accreditation report is delivered to regional administrative authorities and a summary is made available to the public; and (5) regional administrative authorities can use the information contained in the accreditation report to revise hospital budgets. These give rise to a number of paradoxes: (1) the fact that accreditation is mandatory lends itself to ambiguity and likens the process to an inspection; (2) the fact that decision makers can use the information contained in the accreditation report for resource allocation can incite establishments to adopt strategic behaviours aimed merely at complying with the accreditation manual; and (3) there is a tendency for establishments to reduce quality processes to nothing more than the completion of accreditation and to focus efforts on standardizing practices and resolving safety issues to the detriment of organizational development. All accreditation systems must be aware of these paradoxes and decide on the level of government involvement and the relationship between accreditation and resource allocation. With time, accreditation in France could benefit from both a professionally driven system and from the increased amount of freedom to focus on quality improvement which is necessary for organizational development.

See end of article for authors' affiliations

Correspondence to: Correspondence to:
Dr M-P Pomey, Faculty of Management, University of Ottawa, 136 Jean-Jacques Lussier St, OHtawa, ON, KIN 6N5, Canada; pomey@management vottawa.ca

Accepted for publication 1 September 2004
A ccreditation is a means of publicly recognizing that a healthcare organization meets predetermined national standards of operation. It has been proposed for both the public and private sectors and covers a number of domains including community health care, tertiary care, and healthcare systems as a whole. Recognition of the accreditation process is based on an external peer assessment of how well an organization complies with standards and how well it performs. ${ }^{1}$

France adopted this measure in 1996 as part of a major overhaul of its healthcare system ${ }^{2}$ aimed at better meeting the needs of the population and enabling the hospital system to improve the quality of its care. The introduction of such a measure in France, with its history of Jacobinism and centralization, ${ }^{3}$ has generated tensions that have translated into a number of paradoxes. Investigation of the impact of the implementation of quality processes ${ }^{4}$ and of accreditation ${ }^{5}$ in French healthcare organizations has shed light on some of these paradoxes.

This article analyses the particular characteristics of the "French style" accreditation process and how their implementation could result in paradoxes related to quality improvement, professional winners, and objectives. Such a review could provide valuable lessons for the French system and for all nations that have implemented accreditation processes or are in the process of doing so. In addition, other healthcare organizations can learn from the French experience and be more aware of some of the issues and implications of the accreditation process and its limitations when implemented in particular ways.

\section{CHARACTERISTICS OF "FRENCH STYLE" ACCREDITATION}

In France, accreditation has been defined by the National Agency for Health Accreditation and Evaluation (ANAES) ${ }^{7}$ as "an external evaluation procedure independent of healthcare organizations and their administrative bodies, conducted by professionals and concerning all operations and practices. Its purpose is to ensure that standards regarding safety, quality of care and treatment of patients are taken into account by the healthcare establishment". Accreditation in France differs from that in other countries in the following ways: ${ }^{8-10}$

- It is mandatory for all healthcare organizations and must be renewed every 5 years.

- It is conducted by a government agency funded by the public healthcare system, the government, and the healthcare organizations;

- During the accreditation visit the "expert surveyors" (that is, peers) have an obligation to report to the ANAES director all instances of non-compliance with safety rules or of operations liable to jeopardize the life of the users.

- The accreditation visit report is made public. It is delivered to regional healthcare administrative authorities (ARHs) and a summary is made available to the public at the ANAES website. ${ }^{11}$

- The ARHs can use the information in the accreditation report to revise hospital budgets and to plan activities.

These characteristics of the regulatory framework are likely to have an impact on how accreditation is perceived and implemented in 
the French healthcare system. There are some positive impacts and some areas in which quality issues are raised.

On the one hand, accreditation carries a major symbolic value akin to a "brand image" that the establishment can "sell" to healthcare authorities, correspondents, and actual and potential patients. In general, being accredited confers the establishment with symbolic bargaining power against healthcare authorities. This "seal of approval" also allows patients and the population to hold a pre-established positive opinion of the establishment and to create "added value" (in the broad sense of the term) for the environment as a whole.

On the other hand, there are certain ambiguities with respect to the eventual benefits that healthcare organizations can derive from accreditation. Firstly, at the financial level, regional healthcare authorities can use the information provided in the accreditation report to modify an establishment's budget or to force it to gear its resources towards given objectives. Another issue concerns the legal responsibility of hospitals before the administrative and criminal courts. ${ }^{12}$ Certain standards are drawn directly from regulatory obligations. Consequently, non-compliance with certain standards contained in the ANAES accreditation manual could constitute a criminal offence and expose the healthcare organizations to lawsuits. Finally, accreditation has the potential to change practices and the organization. It is legitimate to wonder whether the mandatory nature of accreditation can promote long lasting organizational change..$^{13-15}$

As a result of the above issues, the lack of transparency and the compulsory nature of the French accreditation process can generate major concerns and mistrust in the professionals in the healthcare organisations.

\section{THE PARADOXES}

As they apply at the national, regional and local levels, all of these particular characteristics and issues carry with them paradoxes that must be addressed.

\section{Inspection or accreditation?}

Should what is practised in France be considered accreditation at all? Or is it more of an inspection? These are legitimate questions given that accreditation is mandatory in France while in most countries around the world it is a voluntary process. $^{913}{ }^{15}$ Furthermore, the accreditation is performed by an agency which in large part is publicly funded and government controlled (the agency's director general is nominated by the council of ministers). This is accentuated by the non-confidentiality of the data collected at the accreditation visit since the public has access to the final reports. Thus, it might be concluded that accreditation in France resembles more of an inspection than a continuous quality improvement (CQI) process.

Although it may appear justified to associate the dimensions of quality and safety based on the principle that a safe environment is required to ensure quality care, the modalities of implementation and the underlying philosophy of these processes are different. ${ }^{16}$ Firstly, the health safety of the population is the moral responsibility of the state, as is safety in other areas of life (road safety, fire prevention, law and order, crime prevention, food safety, etc). However, implementation of quality processes-particularly those regarding CQI programmes in health care-is, above all, the responsibility of the professionals who deliver these services.

In addition, the risk of confusion can be prejudicial not only to the healthcare organizations themselves but also to the expert surveyors and the accrediting body. This tendency is reinforced even more by the exposure to legal action inherent in certain standards drawn directly from regulatory texts and incorporated in the accreditation manual. ${ }^{7}$ In this context, expert surveyors find themselves in a "schizoid" position where they are called upon at the same time to inspect/denounce and to advise/help. Thus, the work of the ANAES tends to replace that of the government and can come across as an inquisition. This perception is further fostered by the organization's status as a government agency. The relationship of trust which normally underlies the contract between the accrediting body and the establishment is therefore at risk of being undermined.

The relationship of trust is further weakened by the fact that the accreditation report is delivered to healthcare authorities but the use to which they will put it has never been clearly defined. In addition, the objectives pursued by the ANAES differ from those pursued by the healthcare authorities. Indeed, the ARHs measure the quality of their services according to their own system of standards, which is integrated in the means and objectives contracts they enter into with the healthcare organizations.

The potential of accreditation to bring about change is therefore diluted. It can become an essentially bureaucratic exercise that will not serve thoroughly to review organizational processes in order to improve structures and treatment modalities as a whole. ${ }^{17}$ Moreover, professionals risk being apprehensive and will not seek to use accreditation as an opportunity to review their modes of functioning. In this connection, it has been recognized that the implementation of CQI processes can only come about if healthcare organizations give their consent. ${ }^{18-20}$ Otherwise, such processes risk being interpreted as a control measure instead of an improvement opportunity.

Expert surveyors who are health professionals have to position themselves as evaluators rather than inspectors. Accreditation manuals allow for areas for discussion and for the development of creativity. The data contained in the report help the establishment to learn and progress. All of these elements and facts should, with time, serve to develop relationships of trust and to consolidate the credibility of the process.

\section{Who wins and who loses?}

Accreditation seems to induce professionals to participate heavily in management activities. ${ }^{521} 22$ It provides an excellent opportunity to form multiprofessional and multidisciplinary working groups. These groups make its possible to develop and forge new ties between people and to introduce new working relations geared more towards complementarity $^{523}$ and less towards hierarchical relationships. These new relations emerge primarily from the numerous meetings held during self-assessment to exchange viewpoints regarding the accreditation standards. These forums of exchange thus serve to develop a higher sense of belonging and to create social capital $^{24}$ by giving front line staff the chance to be heard and to have their work receive greater recognition. They also provide a golden opportunity to reflect upon matters and to debate ideas, to refocus on the needs of the clientele, to foster the decentralization of decision making, and for clinical and administrative professionals to work together.

However, it is important not to allow accreditation to become an instrument that will benefit only certain categories of professionals. ${ }^{25}{ }^{26}$ It must prove that there is added value for all professionals, otherwise it risks being devalued not only by physicians and other health professionals but also by administrative staff. Moreover, participation in accreditation risks becoming less "prestigious" and rewarding. ${ }^{27}$ It is already well known that it is difficult to get physicians to take part in accreditation. ${ }^{28} 29$ Instead, under ideal conditions, accreditation preparations should be conducted under a joint leadership ${ }^{30}$ with physicians, nurses, managers and other staff. If this leadership is not there, the legitimacy of the 
process and of the alternative leadership risks being questioned.

\section{Clinical or administrative authority?}

Accreditation provides an opportunity for a hospital's executive to intervene in the clinical sphere. In this regard, administrative managers in France have identified accreditation as a strategic issue and have conferred to it an institutional dimension. ${ }^{829}$ At the same time, they have sought to control the implementation of accreditation processes by assigning operational leadership to a director or administrative officer with reference to an essentially normative model. ${ }^{3}$ This legitimacy was easily acquired because accreditation covers the field of safety for which administrative managers are directly responsible. The problem is that encroachment on the clinical sphere may lead to the disengagement of medical and paramedical professionals from the process. After all, accreditation is of interest precisely because it should allow all professionals to question themselves and to move forward in a climate of trust. The dissemination strategies and the leadership required to conduct the process cannot do without these professionals. ${ }^{31-34}$ Indeed, their disengagement robs accreditation of its capacity for change.

Improving practices or helping budgetary allocation? The open objective of accreditation is to improve quality of treatment for patients and their families. The combination of this with another objective-that of resource allocationcarries the risk of derailing the process because the establishment is liable to adopt strategic behaviours solely with the aim of gaining accreditation instead of "playing the game" according to the rules. Making accreditation mandatory for funding purposes is therefore not recommended. ${ }^{9} 35$ Under such circumstances, the accreditation process risks becoming a mere pretext rather than an opportunity to take stock of quality processes. Notwithstanding, it is possible to use quality processes and accreditation as indicators for modulating budgets, as is presently the case in Luxembourg. ${ }^{36}$

The association of accreditation with funding also carries the risk of seeing the procedure downgraded by the organizations which are liable to overlook the primary objective of conducting a thorough review in order to improve practices and the organization. However, it should be possible to work together with the healthcare organizations to render them more accountable with a view to modulating budgets on clearly defined grounds, including the consideration of efforts to develop and implement measures to foster better quality treatment.

\section{Improvement in practices or capitalization of values?} The initial studies of accreditation and the implementation of quality processes ${ }^{3-5}$ have shown that the major contribution of accreditation preparations has not been the improvement of practices-which is the primary objective of this processbut rather the creation of a forum to discuss the values, knowledge, and cultural heritage shared by the professionals in the organization. The exchanges served to act on the philosophies and presented the opportunity to acquire new ways of thinking. The professionals acquired a more cross sectional vision of both their establishment and their activities. They managed to put their professional activities into perspective with those of other interveners in the treatment process. $^{5}$ A constructive state of mind geared to seeking solutions rather than casting blame therefore emerged. In this regard, accreditation had an impact on a dimension of performance ${ }^{37}$-namely, that of the maintenance of values and of the organizational climate. Furthermore, the healthcare organizations implemented specific structures for developing a documentation management process centred on the implementation of standard documents, protocols and procedures. This initial work should therefore generate improvement in the other dimensions of performance, including the improvement of practices.

\section{DISCUSSION}

\section{Lessons for all accreditation process}

In the French healthcare system, which is funded by social contributions and managed jointly by the state and the stakeholders, $^{38}$ the promotion of the quality of healthcare services is the responsibility of the state rather than of the professional organizations. One reason that the French government has made accreditation mandatory is to guarantee a certain level of quality of hospital care. However, no research and analysis has been performed to determine the impact of implementing the accreditation system on patient care. It would be very difficult to conduct a research study involving the end patient, but it is critical to know more about how quality processes affect the end user since most healthcare organizations are striving to be more "patient centred". It is important to monitor carefully the impact on patient care.

Another reason why the French government decided to implement quality standards for healthcare organizations through the ANAES is because, if they had not intervened, there may still not be any measures in place for evaluating the system. It is characteristic of the French culture to want directions from the state for setting standards and regulations. This is in contrast with other western societies where policies and procedures are driven by professional organizations, companies, special interest groups, and individuals. ${ }^{13}$ Thus, in France, accreditation takes place more at the level of the healthcare system, driven by government, than at the level of each healthcare organization.

Accreditation serves to foster organizational development. However, this development can occur only if there are "spaces of freedom" for the professionals and positive incentive mechanisms for its realization. The spaces of freedom created within this framework should foster creativity and, among other things, draw attention to the innovative work being performed in healthcare organizations. In this connection, a reform of the accreditation manual is underway to produce such spaces. ${ }^{11}$ It is therefore essential to find a modus vivendi that respects "territories" and encourages complementarity so that no one feels abused or damaged. ${ }^{39-43}$ This can be achieved through the creation of forums of debate within the establishment where agreement can be reached in complete openness.

There are several lessons to be learned from this review of the French accreditation system. Firstly, it appears essential to question openly the relevance of making accreditation compulsory in France as in any other country, given the possible risk of running off course. This is all the more true as, in countries where accreditation is not mandatory, the majority of healthcare organizations subscribe to it spontaneously. ${ }^{71}{ }^{21}$ Considering accreditation as a tool for the state to guarantee quality care to the population changes everything. A review of the nature of the bodies in charge of accreditation is recommended to determine whether they should be government agencies or independent professional organizations of corporate interest funded by industry.

A number of authors have pointed out the difficulty in defining quality and the importance of taking into accounts all of its facets. ${ }^{42}{ }^{43}$ This testifies to the fact that we are not here on formal grounds where it is possible to bear a simple judgement when evaluating the quality of services. In this context, by rendering accreditation mandatory as in France, the state has the responsibility of providing the necessary means for delivering quality treatment. 
Finally, there needs to be some understanding that the state does not use the accreditation results for the purpose of financial sanctions. Such a use would have the effect of diminishing — if not cancelling — the benefits of accreditation as a learning tool in favour of a system of penalties. In France the lack of transparency regarding the utilization of accreditation data for funding purposes does not encourage professionals to trust the process. Aside from accreditation, regional administrative authorities (the ARHs) have incorporated appendices comprising plans for monitoring quality indicators in their means and objectives contracts with the organizations. These appendices, which vary from one healthcare organization to the next, are based on elements cited in the accreditation report and may be irrelevant to what is required under accreditation. However, they have the merit of clearly stipulating that they will serve to modulate hospital budgets.

In view of all these differences and their possible reconciliation, it is essential that all the professionals involved in the accreditation process must be aware of these paradoxes so that they can be discussed and overcome. Indeed, it is only through exchanges and a gained awareness that accreditation can contribute not only to the well being of patients and their families but also to that of the professionals in the healthcare organizations.

Many other countries have implemented accreditation systems or are considering their development. It is therefore important that governments understand the issues underlying their choices. Should accreditation related to financial allocation be mandatory or optional? The decision should be made with the knowledge that the ensuing dynamics could prove very different. Also, associating safety with quality without clearly defining the role of health authorities relative to the accrediting body makes it hard to know exactly where the latter stands.

Lessons to improve the accreditation process in France Quality is a continuous process of improvement. In order to further develop and improve the accreditation system in France, the process must take time to realize all of the paradoxes identified and learn from them. It will be crucial for the French healthcare system to discuss whether the accreditation process should remain compulsory, given the current findings. As mentioned, healthcare organizations

\section{Key messages}

- Compulsary accreditation can change the philosophy and intentions of healthcare organizations towards conformity with requirements instead of towards quality improvement.

- If the accreditation standards are linked to health legislation, this acts as a deterrent since it is more like an inspection than an improvement exercise.

- All levels of stakeholders should be included throughout the accreditation process, from front line staff to senior management, so that improvements can filter through the entire organization.

- In the accreditation process it must be clear how the results from the final report will be used and implemented and the accreditation process must be separated from resource allocation so that the focus is on improvement rather than funding for operations.

- More studies are required to assess and review the impact of accreditation on patient care. currently do not have a choice as to whether or not they want to be accredited. They are obliged to ask the ANAES for their accreditation in order to operate. In the past, to institute certain standards of care across the system, government intervention was seen as the only way to oblige all French healthcare organizations to go through the process. However, now there should be opportunities for them to choose whether or not they want to take advantage of the accreditation process. The risk is that France has created a set of strict regulations-a standardization of servicewithout accountability to the quality of the service. There is no guarantee that improvement will result from being accredited. It is time for French healthcare professionals to assume responsibility and not the state through the selfevaluation process. This is seen as a step towards improvement for the French system since healthcare professionals have a vested interest in the quality of their work/service and will take the necessary steps to ensure improvement, rather than the inspector who just ensures that certain standards are met. Further research is also required to see if the accreditation process adds value to healthcare organizations and its impacts on the end user. It will be interesting when comparisons can be made between the different accreditation processes offered by other agencies as to the value created, but this will only be possible when more research has been performed. Finally, the accreditation process must be separated from financial resource allocation. Currently, in France, it is not clear whether or not funding is tied to performance through the accreditation review. This must be changed so that healthcare organizations can focus on continuous quality improvement rather than being involved because of funding implications.

\section{Authors' affiliations \\ M-P Pomey, A Tosh, Faculty of Management, University of Ottawa, Ottawa, ON, K1N 6N5, Canada}

P François, Laboratoire GREQ-Santé, Faculté de médecine, Université de Grenoble, France

A-P Contandriopoulos, Département d'administration de la santé, Faculté de médecine, Université de Montréal, Montreal, Quebec, Canada

D Bertrand, Service de santé publique, Hôpital Fernand-Vidal, Assistance Publique-Hôpitaux de Paris, Paris, France

\section{REFERENCES}

1 International Society for Quality in Health Care. Accreditation and ALPHA Australia (http://www.isqua.org.au/) 2003.

2 Code de la Santé Publique. Ordonnance no 96-346 du 24 avril 1996 portant réforme de l'hospitalisation publique et privée. Paris: Journal Officiel de la République Française, 25 avril, 1996:6324-36.

3 Pomey M-P, Poullier J-P. In search of a philosophical stone: painless adjustement France's Health Policy Conundrum. In: Raffel MW, eds. Health care reform in industrialized countries.2nd ed. PA: Pennsylvania State University Press, 1997

4 Francois P, Pomey M-P. Introduction de la gestion de la qualité dans les établissements de santé français, jeux d'acteurs et transformations induites. Rev Sci Sociales Santé (submitted for publication).

5 Pomey M-P. La préparation à l'accréditation: un outil de changement organisationnel? Ed GRIS. University of Montreal, 2003.

6 Pomey M-P, Contandriopoulos A-P, François $P$, et al. Accreditation as a tool for organizational change. Int J Health Care Qual Ass, 2004;17 (in press).

7 ANAES. Manuel d'accréditation des etablissements de santé. Paris: Agence Nationale d'Accréditation et d'Evaluation en Santé (ANAES), 1999.

8 Giraux A. Accreditation and the quality movement in France. Qual Saf Health Care 2001;10:111-6.

9 Ségouin C. L'accréditation des établissements de santé: de l'expérience internationale à l'application française. Paris: Les dossiers de l'AP-HP, Doin Editeurs, 1998.

10 Bertrand D. Accréditation et qualité des soins, Dossier spécial. Actualité en Santé Publique, June, 18-78.

11 ANAES. Agence Nationale d'Accréditation et d'Evaluation en Santé, France (http://www.anaes.fr/ANAES) 2004.

12 Faugerolas $\mathbf{P}$. Accréditation et responsabilité hospitalière. Revue Hospitalière de France 1999;6:6-21.

13 Scrivens E. International trends in accreditation. Int J Health Plan Manage 1995; 10:165-81. 
14 Scrivens E. A taxonomy of the dimension of accreditation systems. Soc Policy Admin 1996;30:114-24.

15 Hayes J, Shaw C. Implementing accreditation systems. Int J Qual Health Care 1995:7:165-71.

16 Champagne F, Contandriopoulos A-P, Pomey M-P, et al. A. Elaboration d'un cadre conceptuel d'analyse de la sécurité dans les organisations de santé. Ottawa: Division des politiques, Santé Canada, 2002.

17 Badrick T, Preston A. Influences on the implementation of TQM in health care organizations: professional bureaucracies, ownership and complexity. Aust Health Review 2001;24:166-75.

18 Berwick DM. Continuous improvement as an ideal in health care. In: Graham NO, eds. Quality in health care-theory, application and evolution Gaithersburg, MA: Apsen Publication, 1995.

19 McLaughlin CP, Kaluzny AD. Quality management in health care: successes and lessons in implementation. J Contin Educ Health Prof 1995;15:165-74.

20 Motvani J, Sower V, Brasier L. Implementing TQM in the health care sector. Health Care Manage Rev 1996;21:73-82.

21 Duckett SJ. Changing hospitals: the role of hospital accreditation. Soc Sci Med 1983;17:1573-9.

22 Beaumont M. Recherche sur l'efficacité du programme d'agrément du CCASS. Méthodologie et résultats. Maîtrise en Administration des Services de Santé: Faculté de Médecine, Université de Montréal, 2002.

23 Pomey M-P, Gerbaud L, Jarno P, et al. Visites-test des maternités des hôpitaux généraux d'Auvergne et de Bretagne: le référentiel canadien d'agrément. ISIS 1999;1:81-93.

24 Bourdieu P. Le sens pratique. Paris: Éditions de Minuit, 1980.

25 Briand S, Bazin A, Gerbaud L. Perceptions de la qualité dans le secteur sanitaire et impact sur la démarche qualité. Cah Sociol Démograph Méd 2001:41:29-46.

26 François $\mathbf{P}$, Dumont d'Ayot $S$, Fourny $M$, et al. Etude des représentations de la qualité chez les professionnels de santé de l'hôpital. In: Santé Publique: des quartiers à l'Europe. Nancy: Société Française de Santé Publique Editeur, 1998.

27 Clément J-M. Les pouvoirs à l'hôpital, Coll les Cahiers Hospitaliers. Paris: Berger-Levrault, 1995

28 Shekelle PG. Why don't physicians enthusiastically support quality improvement programs? Qual Saf Health Care 2002;11:6.
29 Schwartz RW, Pogge P. Physician leadership: essential skills in a changing environment. Am J Surg 2000;180:187-92.

30 Denis J-L, Lamothe L, Langley A. The dynamics for collective leadership and strategic change in pluralistic organizations. Acad Manage J

2001:44:809-37.

31 Bruneau C, Obrecht $O$, Lachenaye-Llanas $C$. Le point sur l'accréditation: une enquête nationale auprès de diverses catégories de professionnels. Gestions Hospitalières, 2003;13-17.

32 Berwick DM, Nolan TW. Physicians as leaders in improving health care: a new series. Ann Intern Med 1998;128:289-92.

33 Kaiser LR. The physician executive in a changing word. Physician Executive 1999;25:10-7.

34 Davidow SL. Physicians taking the lead to improve patient care. Jt Comm J Qual Improv 1999;25:145-52

35 Roberts MD, James S, Jack G, et al. A history of the Joint Commission on Accreditation of Hospitals. JAMA 1987;258:936-40.

36 Durant G, Segouin C, Lemay A, et al. Comparaison internationale des systèmes de financement des hôpitaux: Belgique-France-QuébecLuxembourg. Epistula-ALASS 2002;46:8.

37 Sicotte C, Champagne F, Contandriopoulos A-P, et al. A conceptual framework for the analysis of health care organizations'performance. Health Serv Manag Res 1998;11:24-48.

38 Fantino B, Fasquel D. Protection contre le risque maladie. In: Pomey M-P, Poullier J-P, Lejeune B. Santé publique. Etat des lieux, enjeux et perspectives. Paris: Ellipses, 2000:498-520.

39 Shortell SM, Levin JL, O'Brien JL, et al. Assessing the evidence on continuous quality improvement: is the glass half empty or half full? Hosp Health Serv Admin 1995; 40:4-24

40 Milakovich ME. Creating a total quality health care environment. Health Care Manage Rev 1991;16:9-20.

41 Firth-Cozens J, Mowbray D. Leadership and quality of care. Qual Saf Health Care 2001;10(Suppl II):ii3-7.

42 Donabedian A. Explorations in quality assessment and monitoring: the definition of quality and approaches to its assessment. Ann Arbor, Ml: Health Administration Press, 1980:163.

43 Haddad S, Roberge D, Pineault R. Comprendre la qualité: en reconnaître la complexité. Ruptures, Revue Transdisciplinaire en Santé 1997;4:59-78. 